\title{
A QUÍMICA ORGÂNICA NA CONSOLIDAÇ̃̃o DOS CONCEITOS DE ÁTOMO E MOLÉCULA
}

\author{
Tânia de Oliveira Camel", Carlos B. G. Koehler" e Carlos A. L. Filgueiras*
}

Instituto de Química, Universidade Federal do Rio de Janeiro, CP 68563, 21945-970 Rio de Janeiro - RJ, Brasil

Recebido em 18/3/08; aceito em 20/6/08; publicado na web em 15/12/08

\begin{abstract}
ORGANIC CHEMISTRY IN THE CONSOLIDATION OF THE CONCEPTS OF ATOM AND MOLECULE. The present work discusses the appearance of the concepts of valence and molecular structure, and describes the appropriation and evolution of the concept of molecule in the period following the publication of Avogadro's Hypothesis. The point of reference is the development of what became known as Organic Chemistry, which encompassed Pharmacy, Physiological Chemistry, Animal and Plant Chemistry, Chemistry of Dyestuffs, Agricultural Chemistry, and the fledgling Organic Synthesis industry in the early $19^{\text {th }}$ century. The theories formulated in these areas and the quest for accurate atomic weights led to those concepts of valence and molecular structure and to a precise differentiation between atom and molecule.
\end{abstract}

Keyword: history of valence; molecular structure; atoms and molecules.

\section{INTRODUÇÃO}

É possível perceber duas correntes explicativas na Química do século XIX: uma consoante à tradição da filosofia natural newtoniana e outra derivada da tradição da história natural. Na primeira, a explicação se faz em termos de corpúsculos elementares, massas e afinidades. Na segunda, a prática da Química Vegetal, Química Animal, Química Agrícola e Química Fisiológica ${ }^{1}$ levou à investigação dos constituintes e produtos derivados de organismos vegetais e animais. Esses produtos, quando analisados, revelaram ter na sua constituição mais simples pelo menos os elementos carbono e hidrogênio. O desenvolvimento das teorias de estrutura molecular dentro de uma tradição da história natural explica as atividades das moléculas químicas na linguagem biológica da forma e da função ao invés da linguagem mecânica de matéria, movimento e força. É nessa tradição e não na de força mecânica, a partir das teorias orgânicas dos tipos e estrutura, que surgiu um dos conceitos mais importantes para o desenvolvimento teórico da Química - o conceito de valência - que permitiu formular o arranjo dos átomos em uma molécula. As teorias dos tipos e estrutura levaram a um questionamento sobre a constituição dos radicais e à aplicação de um atomismo heurístico, contribuindo para a distinção entre átomos e moléculas.

Durante muitas décadas após o átomo de Dalton, as palavras átomo e molécula foram usadas de forma indistinta para descrever qualquer partícula maciça e indivisível que fosse capaz de expressar movimento e força. Dalton se apoiou na filosofia natural newtoniana, adotou como ponto de partida a tabela de 33 elementos do Traité Élémentaire de Chimie de Lavoisier e identificou a diversidade de elementos químicos com os átomos químicos heterogêneos. Diferente de "atomismos" anteriores, o átomo de Dalton decorre da necessidade de explicar as proporções observadas nas reações químicas. O conceito novo e central introduzido por Dalton é o peso atômico e é também sua grande dificuldade. ${ }^{2}$ Como determiná-lo? Esta era a questão. Dalton expressou sua visão no New System of Chemical Philosophy. ${ }^{3}$

Avogadro empregava os termos molécula, molécula integrante,

\#Programa de Pós-Graduação em História das Ciências e das Técnicas e Epistemologia, Centro de Tecnologia, UFRJ

*e-mail: calf@iq.ufrj.br molécula constituinte e molécula elementar. Os historiadores se referem à falta de clareza no uso desses termos. A correspondência conceitual estabelecida pelos historiadores entre os termos de Avogadro e os termos atuais é de molécula integrante com substância composta, molécula constituinte com substância simples diatômica ou poliatômica e molécula elementar com átomo. ${ }^{4} \mathrm{O}$ uso indistinto do termo molécula também é muito comum em seus textos.

Freqüentemente, a hipótese de Avogadro é associada à pesquisa dos pesos atômicos e à teoria atômica, porém Avogadro nunca mencionou o termo átomo em seus trabalhos ou se referiu a suas moléculas como diatômicas ou poliatômicas.

Dalton não concordava com a hipótese de Avogadro de que volumes iguais de gases diferentes continham o mesmo número de partículas e a idéia de que moléculas integrantes se dividiam durante as reações químicas havia sido considerada ad-hoc pelos químicos do período.

Durante a primeira metade do século XIX e até mais adiante há uma confusão quanto à terminologia e quanto à notação empregada. Átomo físico, átomo químico, molécula eram termos que possuíam significados diferentes. Para outros a linguagem dos equivalentes era preferível àquela dos átomos e o uso dos pesos equivalentes ${ }^{5}$ era mais seguro. Os equivalentes eram quantidades empíricas e estavam mais de acordo com a filosofia positivista.

Chegar a um acordo sobre os pesos atômicos e sobre a terminologia empregada era o que se pretendia com o congresso de Karlsruhe em 1860. "Enquanto os químicos tentavam resolver suas diferenças por uma convenção, um debate sobre a realidade dos átomos se estabeleceu a partir de vários resultados obtidos naqueles últimos vinte anos (entre 1840 e 1860). A isomeria e a teoria das substituições em química orgânica, a assimetria dos cristais em cristalografia e a Teoria Cinética dos Gases sugeriam uma organização molecular e atômica.” ${ }^{6}$

\section{TEORIAS INICIAIS EM QUÍMICA ORGÂNICA}

\section{Teoria dos radicais ${ }^{7}$}

Em 1828, Jean Baptiste Dumas e Pierre Boullay sugeriram que os compostos aparentados ao álcool poderiam ser compreendidos como produtos de adição do etileno $\left(\mathrm{C}_{2} \mathrm{H}_{4}\right)$, assim como os compostos amoniacais eram compreendidos como produtos da amônia. É interessante observar que Dumas nessa ocasião postulou uma distinção entre dois 
tipos de partículas: aquelas correspondentes às moléculas, que não poderiam ser divididas por meios puramente físicos, e os verdadeiros átomos químicos, que eram as menores unidades que participavam de qualquer reação química. ${ }^{8}$ Dumas já diferenciava em 1828 a "molécula química" ou "átomo de um corpo simples" que se conserva nas reações químicas e a "molécula física" ou "átomo composto": "átomo de um corpo simples é, portanto, a partícula muito pequena desse corpo que não sofre mais alteração nas reações químicas. $O$ átomo de um corpo composto é só o pequeno grupo formado pela reunião dos átomos simples que o constituem."

Aquilo que Avogadro chamou de molécula, Dumas chamava de átomo. Assim, para Dumas, a água era formada de um átomo de hidrogênio e meio átomo de oxigênio. Na visão de Avogadro, a água era constituída de uma molécula de hidrogênio e meia molécula de oxigênio. ${ }^{10}$

Posteriormente, Liebig e Wöhler publicaram um artigo sobre o óleo de amêndoas amargas, destacando a existência do radical benzoil $\mathrm{C}_{14} \mathrm{H}_{10} \mathrm{O}_{2}$ (na verdade $\mathrm{C}_{7} \mathrm{H}_{5} \mathrm{O}$ ). Berzelius se interessou pelo radical e chegou mesmo a propor uma nomenclatura para representar esses radicais: Bz para o benzoil e E para o etileno. ${ }^{11}$ Para se estruturar um composto utilizando a Teoria dos Radicais era necessário que na composição desse composto houvesse pelo menos uma unidade da fórmula empírica do radical.

O dualismo eletroquímico formulado por Berzelius postulava que cada corpo simples ou composto possui uma polaridade elétrica cuja intensidade varia de acordo com a natureza do corpo. As fórmulas químicas utilizadas por Berzelius indicavam como os átomos polarizados se mantinham unidos em uma molécula ou composto, através de forças ou cargas de natureza elétrica. $\mathrm{O}$ sal amoniacal $\left(\mathrm{NH}_{4} \mathrm{Cl}\right)$ tinha, portanto, a seguinte fórmula racional ou explicativa: $\mathrm{NH}_{3}$. $\mathrm{HCl}^{12}$

A teoria dos radicais ainda se insere no escopo de uma teoria dualística conforme formulada por Berzelius e com isso a unidade da teoria eletroquímica estava preservada. Pode-se dizer que a teoria dos radicais foi a forma como a teoria dualística se expressou na Química Orgânica.

A utilização dos radicais permitiu a formulação de várias substâncias orgânicas e facilitou a nomenclatura, porém as fórmulas dos radicais variavam de pesquisador para pesquisador, pois o peso atômico adotado por cada um deles para um mesmo elemento era diferente. Não era possível, portanto uma generalização dos radicais obtidos. Pensava-se que a constituição de um composto pudesse ser inferida a partir da reação. Deste modo, os radicais já existiriam no composto e seriam libertados durante a reação, o que conflitava com o fato de que os radicais na sua maioria não pudessem ser isolados. ${ }^{13} \mathrm{De}$ acordo com essa idéia uma pluralidade de fórmulas para um mesmo composto se tornava possível, como objetou Gerhardt para o sulfato de bário, que poderia ser $\mathrm{BaO}+\mathrm{SO}_{3}$ ou $\mathrm{BaO}_{2}+\mathrm{SO}_{2}$ ou ainda $\mathrm{BaS}$ $+2 \mathrm{O}_{2}$, uma vez que todos esses radicais podiam ser isolados. ${ }^{14} \mathrm{As}$ Tabelas 1 a 3 ilustram o que foi dito aqui.

\section{Teoria do núcleo}

Dumas, ao explicar a liberação de cloreto de hidrogênio durante a combustão da cera de velas brancas, sugeriu que o "cloro possui
Tabela 1. Compostos derivados do radical etileno. Adaptada da ref. 11

\begin{tabular}{lc}
\hline Etileno & $\mathrm{C}_{2} \mathrm{H}_{4}$ \\
Alcool & $\mathrm{C}_{2} \mathrm{H}_{4}, \mathrm{H}_{2} \mathrm{O}$ \\
Éter sulfúrico & $2 \mathrm{C}_{2} \mathrm{H}_{4}, \mathrm{H}_{2} \mathrm{O}$ \\
Éter clorídrico & $\mathrm{C}_{2} \mathrm{H}_{4}, \mathrm{HCl}$ \\
Éter nítrico & $\mathrm{C}_{2} \mathrm{H}_{4}, \mathrm{HNO}_{2}$ \\
Éter acético & $\mathrm{C}_{2} \mathrm{H}_{4}, \mathrm{C}_{2} \mathrm{H}_{4} \mathrm{O}_{2}$ \\
Éter iodídrico & $\mathrm{C}_{2} \mathrm{H}_{4}, \mathrm{HI}$ \\
\hline
\end{tabular}

Tabela 2. Pesos atômicos de uso comum. Adaptada da ref. 11

\begin{tabular}{lccc}
\hline & $\mathrm{H}$ & $\mathrm{C}$ & $\mathrm{O}$ \\
\hline Berzelius & 1 & 12 & 16 \\
Liebig & 1 & 6 & 8 \\
Dumas & 1 & 6 & 16 \\
\hline
\end{tabular}

o poder singular de se apoderar do hidrogênio de certos corpos e de substituí-lo átomo a átomo". Segundo Dumas, essa reação era um exemplo da "lei de substituição", que juntamente com a "lei de adição" deveria ser uma regra comum de composição e decomposição por meio das quais átomos ou equivalentes e radicais, consistindo em grupos persistentes de átomos, poderiam entrar em combinação.

Dumas enunciou uma lei empírica que pode ser resumida da seguinte forma:

"Quando uma substância contendo hidrogênio é submetida à desidrogenação pela ação de cloro, bromo ou iodo, para cada volume de hidrogênio que ela perde, ela ganha um volume igual de cloro, bromo ou iodo e quando a substância contém água, ela perde o hidrogênio correspondente a essa água sem substituição." 16

O cloro removia os átomos de hidrogênio oxigenados sem substituição, porém substituía átomo a átomo os átomos de hidrogênio que estivessem combinados com carbono. Posteriormente, Dumas considerou a oxidação como uma substituição. Na transformação de álcool etílico em ácido acético, ele concluiu que todo átomo de hidrogênio eliminado era substituído por meio átomo de oxigênio, isto é, hidrogênio, cloro, bromo, iodo eram equivalentes enquanto que o oxigênio tinha o dobro do valor de substituição daquelas espécies.

Entre 1835 e 1840 Laurent repetidamente empregou a idéia de que hidrocarbonetos eram "radicais fundamentais", dos quais vários "radicais derivados" poderiam ser obtidos por reações de substituição. Esses radicais derivados ainda apresentavam essencialmente as mesmas propriedades do radical fundamental, a partir dos quais eles haviam sido preparados. Em 1836, Laurent, assistente de Dumas, multiplicou as experiências do mesmo gênero e afirmou que o cloro substitui no sentido exato, isto é, não só ocupa o lugar, como desempenha o mesmo papel do hidrogênio que ele substitui.

Desta maneira, Laurent questionou a teoria eletroquímica ao

Tabela 3. Fórmulas obtidas por diferentes pesquisadores. Adaptada da ref. 11

\begin{tabular}{|c|c|c|c|c|}
\hline Nome atual & Fórmula atual & & Radicais $^{15}$ & \\
\hline & & $\begin{array}{c}\text { Etileno }-\mathrm{C}_{2} \mathrm{H}_{4} \\
\text { Dumas }\end{array}$ & $\begin{array}{c}\text { Etil }-\mathrm{C}_{2} \mathrm{H}_{5} \\
\text { Berzelius e Liebig }\end{array}$ & $\begin{array}{c}\text { Acetil }-\mathrm{C}_{2} \mathrm{H}_{3} \\
\text { Liebig }\end{array}$ \\
\hline Álcool etílico & $\mathrm{C}_{2} \mathrm{H}_{5} \mathrm{OH}$ & $\mathrm{C}_{2} \mathrm{H}_{4} \cdot \mathrm{H}_{2} \mathrm{O}$ & $\mathrm{C}_{2} \mathrm{H}_{5} \mathrm{O} . \mathrm{H}$ & $\mathrm{C}_{2} \mathrm{H}_{3} \mathrm{O} .3 \mathrm{H}$ \\
\hline Éter etílico & $\left(\mathrm{C}_{2} \mathrm{H}_{5}\right)_{2} \mathrm{O}$ & $2 \mathrm{C}_{2} \mathrm{H}_{4} \cdot \mathrm{H}_{2} \mathrm{O}$ & {$\left[\mathrm{C}_{4} \mathrm{H}_{10} \mathrm{O} \cdot \mathrm{H}_{2} \mathrm{O}\right]$} & {$\left[\mathrm{C}_{4} \mathrm{H}_{6} \mathrm{O} \cdot 6 \mathrm{H}\right]$} \\
\hline Cloreto de etila & $\mathrm{C}_{2} \mathrm{H}_{5} \mathrm{Cl}$ & $\mathrm{C}_{2} \mathrm{H}_{4} \cdot \mathrm{HCl}$ & $\mathrm{C}_{2} \mathrm{H}_{5} \cdot \mathrm{Cl}$ & $\mathrm{C}_{2} \mathrm{H}_{3} \mathrm{Cl} .2 \mathrm{H}$ \\
\hline
\end{tabular}


atribuir ao cloro, um dos elementos mais negativos, o mesmo comportamento do hidrogênio, o elemento mais positivo. Laurent ofereceu em seu lugar uma interpretação geométrica da constituição química.

A teoria do núcleo de Laurent para hidrocarbonetos mantinha que os compostos possuem um núcleo fundamental, dentro do qual as substituições podem ocorrer. O núcleo era representado por um hexaedro com 8 vértices ocupados por 8 átomos de carbono e 12 átomos de hidrogênio colocados no centro das doze arestas $\left(\mathrm{C}_{8} \mathrm{H}_{12}\right)$, Figura 1. O raciocínio de Laurent estava apoiado nos seus conhecimentos de cristalografia mineral e isomorfismo, ${ }^{17}$ no que diz respeito ao arranjo espacial de átomos e moléculas: um composto não é simplesmente uma justaposição, é um bloco único elaborado por substituições progressivas a partir de uma estrutura fundamental. Quando um hidrogênio do núcleo $\mathrm{C}_{8} \mathrm{H}_{12}$ fosse substituído por um átomo de cloro obtinha-se o $\mathrm{C}_{8} \mathrm{H}_{11} \mathrm{Cl}$, um núcleo ou radical derivado. $\mathrm{O}$ núcleo fundamental e o núcleo derivado poderiam ainda reagir por adição para formar, respectivamente, outros compostos como $\mathrm{C}_{8} \mathrm{H}_{12} \mathrm{O}$ (obtido pela adição de $\mathrm{O}$ a $\mathrm{C}_{8} \mathrm{H}_{12}$ ) ou $\mathrm{C}_{8} \mathrm{H}_{11} \mathrm{Cl}_{3}$ (obtido pela adição de $2 \mathrm{Cl}$ a $\mathrm{C}_{8} \mathrm{H}_{11} \mathrm{Cl}$ ). Doze hidrogênios e oito carbonos estão representados pelas esferas escuras. A adição pode ocorrer nas duas menores faces do prisma retangular, enquanto a substituição ocorre nas esferas escuras que não ocupam os vértices, como mostra a Figura 1.

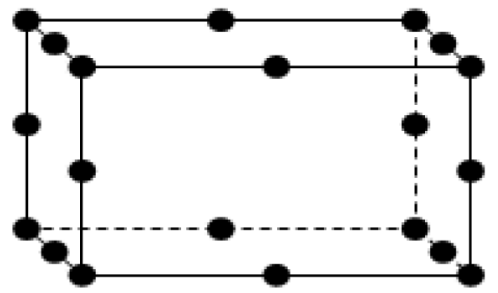

Figura 1. Núcleo Fundamental de Laurent

Esta nova representação traz implicitamente uma mudança do centro de interesse da Química: a molécula e não mais o átomo é a unidade fundamental nos estudos das reações químicas. O átomo representa a menor quantidade de um corpo simples que pode entrar em uma combinação e a molécula representa a menor quantidade de um corpo simples que pode ser empregada para efetuar uma reação química. Em Recherches sur les combinaisons azotées nos Annales de Chimie, publicado em 1846, Laurent se refere às moléculas de corpos simples como, por exemplo, hidrogênio, cloro, bromo, como sendo diatômicas e propondo um mecanismo de substituição para explicar a reação entre hidrogênio e cloro, como se segue:

"A molécula de hidrogênio, cloro(...) é formada de dois átomos que constituem uma combinação homogênea $(\mathrm{HH})$, (ClCl), (MM), etc... Essas combinações homogêneas colocadas em presença umas das outras podem dar lugar a uma dupla decomposição ou a uma substituição e formar desse modo uma combinação heterogênea: $(\mathrm{HH})+(\mathrm{ClCl})$ $=(\mathrm{HCl})+(\mathrm{ClH})$. Admitiremos que cada molécula de corpo simples é ao menos divisível em duas partes que poderemos chamar átomo; essas moléculas só podem se dividir no caso de combinação. Então, cada letra $\mathrm{O}, \mathrm{H}, \mathrm{Cl}$ representa um meio-volume ou meia-molécula ou um átomo.

$O$ átomo de M. Gerhardt representa a menor quantidade de um corpo simples que pode existir em uma combinação. Minha molécula representaria a menor quantidade de um corpo simples que é necessário empregar para operar uma combinação, quantidade que é divisível em dois pelo próprio ato da combinação. Deste modo $\mathrm{Cl}$ pode entrar numa combinação, mas para isso é necessário empregar $\mathrm{Cl}^{2}$. Esta associação binária dos átomos nos permitiria, talvez, explicar também até certo ponto a afinidade que os corpos no estado nascente possuem.

Se colocarmos em contacto duas moléculas $H H^{\prime}$ e BB', a afinidade de B por B'e de H por H'sofrerá talvez por se opor à combinação de B por $H$ e de B'por H'. Mas B e H, esses dois corpos, se não precisam destruir nenhuma afinidade, poderão se combinar mais facilmente. É o que ocorre, por exemplo, se o hidrogênio está no estado nascente, quando se libera do ácido clorídrico... que tenderá a reconstruir uma molécula binária, seja com o bromo, seja com outro átomo de hidrogênio, $\mathrm{HCl}+\mathrm{M}=\mathrm{ClM}+\mathrm{H}$." ${ }^{18}$

O conceito de um núcleo persistente era bastante interessante nessa época para explicar as reações do naftaleno. Este hidrocarboneto reage tanto por adição, que afeta muito suas propriedades, quanto por substituição, que não as afeta. Este comportamento era coerente com o postulado de um núcleo fundamental cuja estrutura se mantinha intacta durante as substituições. Laurent não identificava seu núcleo com a real constituição da molécula, postulando estruturas pré-formadas para explicar as reações, visto que as estruturas não podiam ser inferidas das reações.

\section{"Não nos devemos ocupar com o arranjo real dos átomos, apenas nos certificarmos se o arranjo é ou não o mesmo para este ou aquele corpo." ${ }^{19}$}

Uma vez que essas estruturas eram postuladas, elas podiam ser representadas por hidrocarbonetos que tivessem sido realmente isolados de modo a minimizar seu caráter hipotético. Obviamente, por suas três dimensões, esses núcleos transcendiam a experiência. A justificativa de Laurent para seu modelo era que, com ele, era possível explicar as diferenças entre as reações de substituição, adição e subtração. As adições ocorreriam nas superfícies do prisma. As substituições ocorreriam a partir da remoção de átomos de hidrogênio pertencentes ao núcleo. Era fácil, então, compreender porque o cloro adicionado podia ser eliminado com hidróxido de potássio e o cloro que substituiu o hidrogênio não, pois este último se tinha tornado parte da estrutura, e resistia à deformação. Embora Laurent não fosse sempre consistente em defender posições protetoras em uma molécula, foi a sua crença em estruturas que lhe permitiu repetir insistentemente que o arranjo dos átomos era tão decisivo quanto determinante para sua natureza elétrica. ${ }^{20}$ Suas fórmulas não tinham a pretensão de expressar a constituição real de um composto. Fórmulas análogas significavam constituições análogas. Laurent empregou uma analogia material para explicar reações e fazer previsões. Como resultado do seu trabalho, os químicos começaram a aceitar gradualmente uma teoria unitária, em oposição à teoria dualística de Berzelius. Ele classificou todos os compostos orgânicos baseado nesses núcleos ou radicais e nos núcleos derivados obtidos a partir do radical fundamental. Essa classificação foi adotada por Leopold Gmelin em seu livro-texto de Química. ${ }^{21}$

Dumas, em 1838, investigou a síntese do ácido tricloroacético e estudou suas reações e derivados. Concluiu que o cloro podia desempenhar o papel do hidrogênio e sugeriu que o seu trabalho fornecia evidências contra a Teoria Dualística. ${ }^{22}$ Nessa ocasião, Dumas assumiu para si todo o mérito da teoria das substituições, ignorando inclusive a contribuição de Laurent. A Teoria dos Tipos Químicos proposta por Dumas foi baseada em uma tradição em história natural de classificação de organismos, que ele aprendera com o botânico Augustin-Pyrame de Candolle, autor de uma classificação botânica baseada no conceito de tipo. ${ }^{23}$ 


\section{Teoria dos tipos}

No artigo "Mémoire sur la loi des substitutions et la théorie des types", Dumas expôs uma linguagem sistemática e uma teoria para a química baseadas nas concepções de tipo, gênero e família natural. O tipo químico e o mecânico introduzidos por ele eram semelhantes ao núcleo fundamental e núcleo derivado estabelecidos por Laurent, embora, como já foi explicado, sejam teorias distintas, principalmente quanto a suas origens conceituais. No referido artigo, Dumas apresentou e discutiu três proposições a respeito das reações de substituição, conforme o texto abaixo:

"A experiência prova que um corpo pode perder um de seus elementos e adquirir um outro substituto, equivalente a equivalente; isto é o que ocorre, em geral, na substituição(...) Todos os corpos produzidos por substituição apresentarão o mesmo grupo e se classificarão no mesmo tipo molecular. Aos meus olhos, eles constituem uma família natural(...)

Entre os corpos produzidos por substituição, há um grande número de corpos que conservam de maneira evidente o mesmo caráter químico, exercendo o mesmo papel de ácido ou de base(...) São esses corpos que eu considerei como pertencentes ao mesmo tipo químico, os que fazem parte do mesmo gênero, para falar a mesma linguagem dos naturalistas(...) O álcool, o ácido acético hidratado e o ácido cloroacético pertencem à mesma família natural. O ácido acético e o ácido cloroacético fazem parte do mesmo gênero...."24

O tipo era uma estrutura unitária na qual um átomo ou grupo de átomos mantinha junto consigo outro átomo ou grupo(s). De acordo com Dumas o tipo químico não é essencialmente alterado pela substituição, e o tipo mecânico é criado pela adição ou eliminação.

Uma outra versão da teoria unitária foi proposta por Charles Gerhardt. Ele escreveu fórmulas para os compostos orgânicos baseado na Teoria dos Resíduos. Para muitos, a Teoria dos Resíduos foi considerada uma segunda Teoria dos Radicais, pois seus resíduos tinham muitas vezes as fórmulas dos radicais dualísticos que os químicos antigos supunham ter livre existência. Gerhardt se opunha frontalmente a isso, visto que seus resíduos não possuíam características elétricas e ele nunca afirmou que eles estavam presentes como tais nas moléculas. Na Teoria dos Resíduos, certos compostos inorgânicos são tão estáveis que podem ser formados a partir de compostos orgânicos com grande facilidade. Este fato promove a formação de resíduos orgânicos que se combinam e formam novos compostos. Desse modo, as reações químicas podem ser entendidas como decomposições, seguidas por trocas entre resíduos e combinações posteriores. ${ }^{25}$

Gerhardt, como Laurent, também não acreditava que a constituição química pudesse ser inferida a partir das reações químicas. Ele acreditava que mesmo substâncias como água, amônia, cloreto de hidrogênio eram produtos de reação, o que não provava que essas substâncias já estivessem presentes como tais, no composto a partir do qual elas foram obtidas. Seus radicais deviam ser considerados apenas como resíduos que podiam combinar-se com outros radicais (resíduos) para formarem compostos, porém não como radicais que pudessem ser isolados. Em síntese, os resíduos de Gerhardt eram completamente imaginários, úteis apenas para explicar as reações. Ele estabeleceu claramente que suas fórmulas nunca representavam a constituição real dos compostos, somente suas reações. Conseqüentemente, um mesmo composto poderia ter fórmulas diferentes quando participava de reações diferentes. Nos dois volumes de seu Précis de Chimie Organique, publicado em 1844-45, Gerhardt defendeu o uso de fórmulas empíricas exclusivamente, porque ele não via nenhum modo de estabelecer a estrutura real dos compostos orgânicos. Qualquer arranjo espacial atribuído a átomos em uma fórmula era meramente por conveniência em descrever uma reação particular ou conceito e, portanto, não tinha significado real. Foi também no Précis de Chimie Organique que Gerhardt desenvolveu as três séries de classificação dos compostos orgânicos: homóloga, heteróloga e isóloga.

Para Gerhardt a "única coisa positiva” era retomar as relações de composição fornecida pela análise elementar e traduzida pela fórmula bruta dos compostos. Na concepção de Laurent e de Gerhardt, um tipo era uma possibilidade de suporte material das transformações químicas que persistia apesar das suas substituições. Em seu Traité de Chimie Organique, em quatro volumes publicados entre 1853-1856, Gerhard ${ }^{26}$ atacou a crença de que fórmulas químicas são capazes de expressar a constituição. Por volta de 1843, Gerhardt estudou os compostos formados em reações com eliminação de água. Nessas reações ocorriam decomposições seguidas de troca de resíduos e formação de água, como na equação abaixo, entre o álcool etílico e o ácido nítrico, redigida segundo a notação de Gerhardt: ${ }^{27}$

$$
\mathrm{C}_{4} \mathrm{H}_{6} \mathrm{O}+\mathrm{HNO}_{5} \rightarrow \mathrm{C}_{4} \mathrm{H}_{5}, \mathrm{NO}_{5}+\mathrm{H}_{2} \mathrm{O}
$$

Uma outra questão que Gerhardt enfrentou diz respeito aos pesos moleculares e atômicos. O sistema adotado então por Gerhardt era o de Liebig, que resultava em fórmulas dobradas. Gerhardt observou que muitas dessas fórmulas podiam ser divididas por dois, como por exemplo, no caso do álcool, de $\mathrm{C}_{4} \mathrm{H}_{12} \mathrm{O}_{2}$ para $\mathrm{C}_{2} \mathrm{H}_{6} \mathrm{O}$, o que resultava numa fórmula em peso compatível com a hipótese de Avogadro, conhecida também como hipótese de Ampère. Ele observou que água, amônia, cloreto de hidrogênio e dióxido de carbono no sistema de quatro volumes eram sempre eliminados com fórmulas dobradas: $\mathrm{H}_{4} \mathrm{O}_{2}, \mathrm{~N}_{2} \mathrm{H}_{6}, \mathrm{C}_{2} \mathrm{O}_{4} \mathrm{e} \mathrm{H}_{2} \mathrm{Cl}_{2}$. Dividir as fórmulas dos compostos orgânicos significava que esses produtos seriam eliminados de acordo com as fórmulas de Berzelius. Essa observação foi posteriormente corroborada pelos trabalhos de Régnault sobre os calores específicos dos compostos. Gerhardt passou a adotar o sistema que relacionava uma fórmula do composto orgânico no estado gasoso com dois volumes de hidrogênio. A consequiência imediata da inovação de Gerhardt foi a substituição dos pesos equivalentes do carbono e do oxigênio pelos seus respectivos pesos atômicos (6 por 12 no caso do carbono e 8 por 16 no caso do oxigênio)

Gerhardt elaborou um mecanismo de previsão e classificação baseado no seu conceito de séries homólogas introduzido anteriormente por J. Schiel (1842). Gerhardt predisse as propriedades de novos compostos por meio de analogias formais estabelecidas entre suas fórmulas empíricas. Se as propriedades físicas variavam uniformemente ao longo de uma série homóloga, qualquer lacuna na série poderia ser detectada. Ele nunca visualizou suas fórmulas-tipo como estruturas. Os tipos ou radicais agiam como um bloco que se transportava de um corpo a outro. Cada um deles podia ser caracterizado por um valor de substituição. Eles se comportavam como unidades, elementos. O radical de Gerhardt era apenas um esquema taxonômico que mostrava as analogias. Seu radical não representava um grupo estável de átomos, mas somente um grupo de compostos, um grau de classificação. As fórmulas escritas por Gerhardt não tinham nenhum caráter ontológico, e ele as denominava "fórmulas racionais", admitindo que para um mesmo corpo era possível atribuir várias fórmulas.

As analogias de Gerhardt eram puramente formais, baseadas em relações numéricas, diferentemente de Laurent, que estabelecia analogias materiais. Talvez essa seja a diferença mais fundamental entre os dois. ${ }^{28}$ Posteriormente uma nova Teoria dos Tipos se desenvolveu, e em 1853 havia quatro tipos: o hidrogênio, o cloreto de hidrogênio, a água de Williamson e a amônia de Wurtz e Hofmann. A partir desses tipos era possível, por substituição, deduzir os álcoois, 
os ácidos, as aminas, etc. Por exemplo, a partir do tipo água, no qual um dos hidrogênios é substituído por um radical hidrocarboneto como metil, etil ou propil tornava-se fácil classificar a série homóloga dos álcoois. O radical ou resíduo de Gerhardt é um grupo de elementos que pode ser transportado de um corpo a outro sob o efeito de uma dupla decomposição. ${ }^{29}$

De acordo com os tipos, Williamson e Gerhardt escreviam o ácido acético como um membro do tipo água, como no Esquema 1:

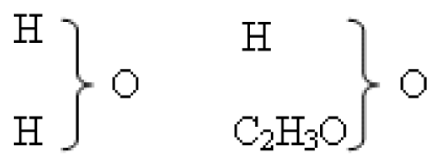

Esquema 1

Desta forma seria possível preparar o anidrido correspondente, como no Esquema 2:

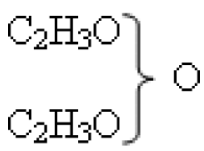

Esquema 2

Gerhardt realmente preparou tais compostos em seu laboratório. As fórmulas passaram a ter também um caráter de previsão, ao invés de serem úteis apenas para classificação. A Teoria dos Tipos permitiu, portanto, uma aproximação para a Teoria Estrutural. ${ }^{30}$

Em 1857, Kekulé propôs o tipo gás dos pântanos $\left(\mathrm{C}_{2} \mathrm{HHHH}\right)$, ainda com o átomo de carbono dobrado como era costume na Alemanha, e que já havia sido proposto em 1855 por Odling. Williamson introduziu o tipo condensado, escrevendo o tipo água sob a forma de dímero ou trímero como denominado atualmente. $\mathrm{O}$ tipo condensado era capaz de explicar os poliácidos ou moléculas como a da glicerina, de acordo com a notação usada para escrever o ácido sulfúrico, como se mostra no Esquema 3:

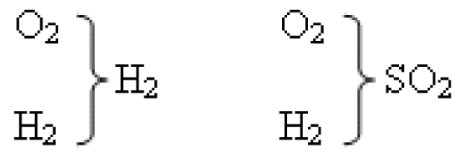

Esquema 3

\section{Pesos moleculares e o conceito de molécula}

O cálculo dos pesos moleculares era um assunto de incertezas no meio do século XIX. Ainda havia discordâncias sobre o peso atômico do carbono e do oxigênio. Gerhardt havia utilizado os pesos equivalentes no seu livro Traité de Chimie Organique publicado em 1856, enquanto sua reforma dos pesos atômicos havia sido relegada a um apêndice no quarto volume, embora ele mesmo defendesse um outro sistema de notação apoiado na hipótese de Avogadro. Como citou Lothar Meyer posteriormente: "do contrário ninguém o teria comprado." ${ }^{31}$ Kekulé adotou a mesma estratégia 5 anos mais tarde. Isto quer dizer que os equivalentes constituíam a linguagem da química da sala de aula em torno de 1860. Devido a dois acidentes felizes, Gerhardt foi capaz de estimar pesos moleculares consistentes em química orgânica: primeiro, nenhuma das substâncias inorgânicas simples como hidrogênio, cloro ou oxigênio, que ele tomou como referência, apresentava densidade de vapor anômala e, segundo, a valência era constante na química orgânica. ${ }^{32}$ No entanto, sua suposição que metais são equivalentes ao hidrogênio, no sentido que eles podem ser substituídos por átomos de hidrogênio, levou-o à metade dos pesos atômicos de Berzelius para os metais que agora chamamos divalentes e a infinitas complicações com metais de valência variável tais como o ferro.

Gaudin, próximo a 1833, já havia insistido que até que se pudesse provar que meias moléculas de hidrogênio e de cloro ${ }^{33}$ pudessem ser divididas, elas deveriam ser tomadas por átomos:

\begin{abstract}
"Uma molécula de gás hidrogênio ao se combinar com uma molécula de cloro forma duas moléculas do gás cloreto de hidrogênio. Para que a combinação ocorra e para que as moléculas compostas observem a mesma distância que as moléculas dos gases componentes é necessário e suficiente que cada molécula componente se divida em duas e, até que se prove que essas metades de molécula ainda se dividem posteriormente, nós as tomaremos por átomos. Logo, os gases cloro, hidrogênio e cloreto de hidrogênio são diatômicos." 34
\end{abstract}

E como Cannizzaro também viria a sugerir em 1860, Gaudin havia usado o calor específico e o isomorfismo como princípios complementares à determinação dos pesos atômicos empregando a hipótese de Avogadro, ${ }^{35}$ uma vez que todos os métodos de determinação de pesos atômicos tinham suas exceções. ${ }^{36} \mathrm{~A}$ citação seguinte foi retirada do livro L'Architecture du Monde des Atomes, escrito por Marc-Antoine Gaudin, e ilustra a distinção entre átomo e molécula de acordo com a Hipótese de Avogadro.

"Poderemos na nossa discussão representar um volume por uma única molécula e não um átomo, o que é muito diferente. Por exemplo, (...) para produção de água, que a relação seja de dois volumes de hidrogênio contra um só volume de oxigênio e após a combinação(...)reconhece-se que ela apresenta, para três volumes de gás empregado, dois volumes de vapor somente...

Pode-se dizer que duas moléculas de hidrogênio, ao se combinarem com uma só molécula de oxigênio, formam duas moléculas de vapor d'água. Então, é necessário que a molécula de oxigênio se divida em duas partes iguais para que cada metade se reúna às moléculas diatômicas de hidrogênio. A molécula de oxigênio, portanto, sendo divisivel por dois, não é um átomo e essa molécula é no mínimo diatômica." ${ }^{37}$

Outras referências ao conceito de molécula são encontradas no trabalho de Laurent de 1846, intitulado Recherches sur les combinaisons azotées, e na justificativa que Williamson forneceu em 1850 para os pesos atômicos de Gerhardt. ${ }^{38}$

Williamson iniciou seu trabalho em 1850 com a intenção de preparar álcoois substituídos assim como Hofmann havia preparado amônias substituídas. Muitos químicos ainda descreviam o álcool etílico e o éter a partir das hipóteses da antiga Teoria dos Radicais. Por exemplo, para Dumas o álcool era $\mathrm{C}^{8} \mathrm{H}^{8}, \mathrm{H}^{4} \mathrm{O}^{2}$ e o éter $\mathrm{C}^{8} \mathrm{H}^{8}, \mathrm{H}^{2} \mathrm{O}$; para Liebig o álcool era $\mathrm{C}_{4} \mathrm{H}_{10} \mathrm{O}, \mathrm{H}_{2} \mathrm{O}$ e o éter $\mathrm{C}_{4} \mathrm{H}_{10} \mathrm{O}$, enquanto para Berzelius o álcool era $\mathrm{C}^{2} \mathrm{H}^{6} \mathrm{O}$ e o éter era $\mathrm{C}^{4} \mathrm{H}^{10} \mathrm{O}$.

Williamson reconheceu a relação entre éter e álcool etílico e provou por reações químicas que o éter etílico continha o dobro de carbonos presentes no álcool etílico, conforme Gerhardt já havia insistido, apoiado nos seus conhecimentos obtidos por analogia. Laurent, em 1846, também já havia concluído que o álcool etílico e o éter etílico eram compostos análogos à água, usando o conceito 
de densidade de vapor. ${ }^{39}$ A partir da demonstração de Williamson, os químicos passaram a dar mais atenção à hipótese física de Avogadro, pois o conceito de densidade de vapor decorre da Hipótese de Avogadro.

Williamson nessa ocasião propôs o tipo água. "Álcool é água, na qual metade do hidrogênio foi substituída por carbureto de hidrogênio $\left(\mathrm{C}_{2} \mathrm{H}_{5}\right)$, e éter é água, na qual ambos os hidrogênios foram substituídos pelo carbureto de hidrogênio." 40

Em 1860, Cannnizzaro distribuiu por meio de Angelo Pavesi sua monografia denominada Sunto di un corso di filosofia chimica (1858) no Congresso de Karlsruhe. A partir do conhecimento adquirido nos últimos 50 anos, Cannizzaro ofereceu uma definição pragmática e ao mesmo tempo oportuna de átomo químico e de peso atômico:

"As diferentes quantidades de um mesmo elemento contidas em diferentes moléculas são todas múltiplos inteiros de uma mesma quantidade, que sendo sempre inteira, tem o direito de ser chamada átomo." 41 "É o menor peso de um elemento descoberto no peso da molécula-grama de seu composto." 42

Com essa afirmativa, Cannizzaro subordinou o átomo à molécula. A atitude de Cannizzaro é a antítese da atitude de Dalton, ${ }^{43}$ e para mostrar como as idéias de Cannizzaro se difundiram rapidamente na Química, é suficiente observar a história da classificação periódica: em 1864, Newlands falhou quando tentou convencer os seus contemporâneos da validade do princípio periódico. Sua falha foi quase inteiramente devida aos pesos atômicos errados que ele empregou. Mendeleev, 5 anos mais tarde, em 1869, obteve sucesso com os pesos atômicos de Cannizzaro.

Em 1865, a primeira tentativa para estimar o diâmetro de uma molécula foi feita por Loschmidt a partir de seu caminho livre médio e do volume molecular. Independentemente dele e de cada um, Stoney em 1868 e W. Thomson em 1870 publicaram resultados semelhantes. Como assinalou na época J. C. Maxwell, "o principal resultado que parece ter sido estabelecido é que a determinação da massa de uma molécula é um legítimo objeto de pesquisa científica e que essa massa não é de nenhum modo impossível de ser mensurada." ${ }^{4}$

Cannizzaro propôs em sua monografia de 1858 uma reforma do ensino de Química através da adoção dos pesos atômicos corrigidos por Laurent-Gerhardt e da hipótese de Avogadro.

A monografia de Cannizzaro impressionou fortemente Lothar Meyer, químico alemão que havia estudado com Bunsen e Kirchhoff, de tal forma que em 1864 ele publicou o primeiro livro de Química organizado dedutivamente, Die Modernen Theorien der Chemie, no qual desenvolveu a teoria química a partir da Hipótese de Avogadro.

A aparente facilidade com que Meyer removeu as dúvidas e incertezas no seu livro foi de crucial importância para a eventual aceitação da hipótese pelos professores de química. ${ }^{45}$ Esse livro foi traduzido para inglês e francês e teve várias edições, pelo menos cinco. A partir da $2^{\mathrm{a}}$ edição, Meyer incorporou seu sistema de classificação periódica dos elementos. Para Partington, o livro de Lothar Meyer "é uma declaração extraordinariamente clara dos princípios fundamentais da química, que teve uma grande influência." ${ }^{46}$

Wurtz adotou o novo sistema de Cannizzaro em 1863 e Odling, em 1864, baseou sua tabela periódica nele. Mesmo assim, os pesos atômicos de Cannizzaro levaram muito tempo para serem adotados. Kekulé, em 1865, ainda insistia na não identidade entre átomos físicos e químicos, na tradição de Gerhardt. Com toda essa hesitação entre os professores da nova química, outros debates se sucederam na Chemical Society ${ }^{47}$ em Londres em 1869, e no Institut de France em 1877.

\section{Valência e estrutura}

O conceito de valência química surge no âmbito da Química Orgânica. Em 1849, Hermann Kolbe submeteu acetato de potássio à eletrólise e obteve um gás que ele acreditou fosse metil livre, mas que se tratava de etano. Quase na mesma época, Edward Frankland tratou iodeto de etila com zinco e isolou o que ele pensava ser etil livre, mas que se tratava de butano, como representado na equação abaixo:

$2 \mathrm{C}_{2} \mathrm{H}_{5} \mathrm{I}+\mathrm{Zn} \rightarrow \mathrm{C}_{4} \mathrm{H}_{10}+\mathrm{ZnI}_{2}$

A reação acima dava origem também a um subproduto, o dietilzinco, que foi o precursor da classe dos organometálicos. Frankland continuou suas investigações com outros metais e verificou que um metal apresentava sempre a mesma capacidade de saturação em relação a um tipo de radical, e mesmo quando este era modificado essa regularidade se mantinha.

Esperava-se que a idéia de valência surgisse vinculada aos compostos inorgânicos, mesmo que o reconhecimento crescente em usar a densidade de vapor para determinar os pesos moleculares e as fórmulas moleculares fosse mais aplicado aos compostos voláteis. Compostos contendo metais, dos quais poucos são voláteis, ainda eram considerados como receptivos às regras arbitrárias de Dalton e era costume escrever os óxidos metálicos, por exemplo, como do tipo binário $\mathrm{MO}(\mathrm{NaO}, \mathrm{CaO}, \mathrm{CuO}, \mathrm{FeO} \ldots)$, de modo que qualquer indício da valência específica se tornava obscuro.

Foi a observação da combinação de fragmentos orgânicos com metais que levou Frankland ao conceito de capacidade de combinação, ou como ficou estabelecido posteriormente - valência. Atribui-se, portanto, a Frankland a identificação prioritária das regularidades existentes nas capacidades de combinação dos metais com radicais orgânicos. A idéia do conceito está explícita num artigo de 1852, On a New Series of Organic Compounds Containing Metals:

"Quando as fórmulas de compostos químicos inorgânicos são consideradas, até um observador superficial fica impressionado pela simetria geral de sua construção. Os compostos de nitrogênio, fósforo, antimônio e arsênio, especialmente, exibem a tendência de estes elementos formarem compostos contendo 3 ou 5 equivalentes de outros elementos, e é nessas proporções que suas afinidades são mais bem satisfeitas. Assim, no grupo ternário temos: $\mathrm{NO}_{3}, \mathrm{NH}_{3}, \mathrm{NI}_{3}, \mathrm{NS}_{3}, \mathrm{PO}_{3}$, $\mathrm{PH}_{3}, \mathrm{PCl}_{3}, \mathrm{SbO}_{3}, \mathrm{SbH}_{3}, \mathrm{SbCl}_{3}, \mathrm{AsO}_{3}, \mathrm{AsH}_{3}, \mathrm{AsCl}_{3}$, etc, e no grupo de cinco átomos $\mathrm{NO}_{5}, \mathrm{NH}_{4} \mathrm{O}, \mathrm{NH}_{4} \mathrm{I}, \mathrm{PO}_{5}, \mathrm{PH}_{4} \mathrm{I}$, etc. Sem oferecer nenhuma hipótese sobre este grupo simétrico de átomos, é bastante evidente dos exemplos dados que tal tendência ou lei prevalece, e que, não importa o caráter dos átomos que estabelecem a união, a força de combinação do elemento atraente, se me for permitida a utilização do termo, é sempre satisfeita pelo mesmo número desses átomos." 48

A força de combinação, que também ficou conhecida como capacidade de saturação, era uma nova expressão para a antiga idéia de afinidade dos elementos.

As fórmulas em Tipo implicavam que os elementos como os radicais possuíam um valor de substituição ou de combinação determinado. Já se admitia que o enxofre e o oxigênio possuíssem um valor de combinação duas vezes maior que o hidrogênio e o cloro; o nitrogênio um valor três vezes maior; carbono e silício quatro vezes maior. Tornou-se importante estabelecer essa capacidade de combinação para os elementos, como já vinha sendo feito com os radicais. Era comum referir-se a essa capacidade de combinação com os termos mono-, di-, tri- e tetratômico. ${ }^{49} \mathrm{O}$ poder de combinação foi expresso 
como atomicidade ou unidades de afinidade. As regularidades observadas por Frankland eram restritas e não chegaram a constituir uma teoria. Havia ainda uma série de contra-exemplos quando os elementos considerados apresentavam capacidade de combinação variável. Posteriormente, a noção de atomicidade foi se diferenciando da noção de valência. ${ }^{50}$ Em 1865 A W. Hofmann, em seu livro texto Introduction to Modern Chemistry, sugeriu que o termo atomicidade ficasse restrito apenas para a composição de moléculas elementares, e introduziu o termo quantivalência. ${ }^{51}$ De acordo com a sugestão de Hofmann, a atomicidade se referia ao número de átomos necessários para constituir uma molécula da substância simples e valência se relacionava com a capacidade de combinação do elemento. Os elementos passaram a ser descritos como mono-, di-, tri- e tetravalente.

Paralelamente, questões que envolviam mecanismos diferentes de reação indicavam que os radicais não podiam mais ser tratados como corpos simples. Fenômenos como isomeria e polimorfismo pareciam demonstrar que o arranjo dos átomos em uma molécula devia afetar as propriedades dos compostos. Os químicos não podiam mais ficar indiferentes à maneira como os átomos elementares estavam ligados entre si nos corpos compostos e a constituição do radical deveria ser considerada. Seja o que Kekulé chamou de constituição, Kolbe de pontos de ataque da afinidade ou Butlerov de estrutura, o fato é que se tornava necessário conhecer o arranjo dos átomos.

Como escreveu Kekulé em 1858:

\begin{abstract}
"Pelo contrário, acredito que devemos estender nossas considerações às constituições dos próprios radicais, que devemos determinar as relações dos radicais entre si e que devemos derivar a natureza dos radicais, assim como dos seus compostos, da natureza dos elementos." 52
\end{abstract}

A idéia de Kekulé sobre a constituição dos compostos orgânicos, baseada na atomicidade dos elementos, representava um nítido movimento do intelecto para o interior de pequenas moléculas invisíveis.

Este movimento também foi observado na Física. Em 1857, Rudolf Clausius, professor de Física do Instituto Politécnico de Zurique, publicou um artigo denominado Über die Art der Bewegung, welche wir Wärme nennen (Sobre o tipo de movimento que denominamos calor). Nele, Clausius estendeu o modelo de Krönig de 1856 ao tentar hipóteses mais convincentes sobre mecânica molecular, e uma explicação mais verdadeira do estado de movimento das moléculas. Considerando apenas o movimento de translação, como fizera Krönig, Clausius não poderia explicar o calor específico observado para os gases, pois para muitos deles o movimento de translação das moléculas não era suficiente para dar conta da energia total do sistema. ${ }^{53}$

Além disso, considerações independentes sugeriam que as moléculas não eram esferas elásticas macias e as colisões também não poderiam ser consideradas como perfeitamente elásticas, pois uma molécula é um corpo complexo, isto é, "a combinação de vários átomos" e, conseqüentemente, espera-se que os átomos vibrem durante e após o impacto.

Num artigo de 1857, Ueber die s.g. gepaarten Verbindungen und die Theorie der mehratomigen Radicale ${ }^{54}$ (Sobre as ligações denominadas casadas e a teoria dos radicais poliatômicos), Kekulé considerou que as moléculas consistiam em uma "justaposição contígua” de átomos. Átomos simples ou radicais poliatômicos (polivalentes) serviam para unir outros átomos ou radicais dependendo da quantidade de afinidade (valência) dos vários componentes. Os átomos podiam ser monoatômicos $(\mathrm{H}, \mathrm{Cl}, \mathrm{Br}, \mathrm{K})$, diatômicos $(\mathrm{S}, \mathrm{O})$, triatômicos $(\mathrm{N}$, $\mathrm{P}, \mathrm{As})$ ou tetratômicos (C). Cadeias grandes e complexas poderiam ser formadas seguindo essas regras de valência. ${ }^{55}$

Kekulé parece ter apreendido o real significado do conceito de valência durante seus estudos sobre a reação do ácido acético com pentassulfeto de fósforo, na qual se obtém o ácido tioacético, e do ácido acético com pentacloreto de fósforo, na qual se produz cloreto de acetila. Com essa analogia, Kekulé tomou consciência da diferença na capacidade de combinação. É evidente da sua observação que com o pentacloreto de fósforo o produto é quebrado, enquanto com o pentassulfeto de fósforo isso não acontece: "a quantidade de enxofre que é equivalente a dois átomos de cloro não é divisível". Empregando os pesos atômicos de Gerhardt, ele concluiu que "o enxofre, como o oxigênio, é dibásico, de modo que um átomo é equivalente a dois átomos de cloro." ${ }^{56} \mathrm{O}$ Esquema 4 mostra a forma de raciocinar de Kekulé neste caso.

$$
\begin{aligned}
& \left.\left.\begin{array}{r}
5 \mathrm{C}_{2} \mathrm{H}_{3} \mathrm{O} \\
\mathrm{H}
\end{array}\right\} \mathrm{O}+\mathrm{P}_{2} \mathrm{~S}_{5} \rightarrow_{\mathrm{H}}^{5 \mathrm{C}_{2} \mathrm{H}_{3} \mathrm{O}}\right\} \mathrm{S}+\mathrm{P}_{2} \mathrm{O}_{5} \\
& \left.\begin{array}{r}
5 \mathrm{C}_{2} \mathrm{H}_{3} \mathrm{O} \\
\mathrm{H}
\end{array}\right\} \mathrm{O}+2 \mathrm{PCl}_{5} \rightarrow 5 \mathrm{C}_{2} \mathrm{H}_{3} \mathrm{OCl}+\mathrm{P}_{2} \mathrm{O}_{5}+5 \mathrm{HCl}
\end{aligned}
$$

Esquema 4

A questão do carbono foi investigada quase simultaneamente por Friedrich August Kekulé e Archibald Scott Couper. Num artigo de 1858, Ueber die Constitution und die Metamorphosen der chemischen Verbindungen und ueber die chemische Natur des Kohlenstoffs ${ }^{57}$ (Sobre a constituição e as metamorfoses das ligações químicas e sobre a natureza química do carbono.), Kekulé mostrou que o carbono era tetratômico, isto é, apresentava quatro "unidades de afinidade", pelas quais ele poderia unir-se a quatro elementos monoatômicos como o hidrogênio ou a dois elementos diatômicos como o oxigênio. Contudo, mais relevante foi acrescentar que o carbono poderia usar uma de suas afinidades para se unir a outro carbono, isto é, que o carbono apresentava a possibilidade de construir cadeias. "O carbono é tetratômico,... ele se combina consigo mesmo." ${ }^{58}$

De acordo com esta perspectiva o esqueleto de carbono tornouse a base dos compostos orgânicos. ${ }^{59} \mathrm{~A}$ teoria de cadeias carbônicas fornecia uma explicação para as séries homólogas que Gerhardt havia introduzido.

Kekulé desenvolveu a idéia de que um átomo de carbono pode usar uma das suas quatro unidades de afinidade para se unir a um outro átomo de carbono formando uma cadeia. No mesmo artigo de 1858, Kekulé afirmou que, no caso de dois carbonos, a valência aparente era seis e não oito, pois uma das valências de cada carbono era satisfeita pela combinação de carbono com carbono, e nesse caso essas duas valências não estariam disponíveis para outros átomos. Kekulé usou a palavra esqueleto em $1858 .{ }^{60}$ Ele havia proposto uma ligação simples entre átomos idênticos de carbono para explicar as cadeias carbônicas e não via nenhuma razão pela qual as ligações múltiplas não poderiam ocorrer entre átomos de carbono como elas ocorriam, sem dúvida, entre oxigênio e carbono e entre nitrogênio e carbono. ${ }^{61}$ Com essa suposição, ele poderia manter constante a valência quatro do carbono.

Kekulé entendia que a valência de um elemento deveria ser fixa e que possuía valor máximo de quatro unidades como nos elementos carbono e silício. Ele teve dificuldades em aplicar seu princípio de valência constante a outros elementos. Durante a formação de qualquer composto, todas as unidades de afinidade eram completamente utilizadas para formar as ligações químicas, e não havia, segundo ele, unidades de afinidade livres. Para acomodar compostos nos quais o 
elemento se apresentava com capacidades de combinação maiores e "salvar" a noção de valência fixa, Kekulé criava hipóteses ad-hoc, como sugerir a diferenciação entre compostos atômicos e compostos moleculares. Esse foi o caso do pentacloreto de fósforo $\left(\mathrm{PCl}_{5}\right)$, que ele escrevia como $\mathrm{PCl}_{3} \cdot \mathrm{Cl}_{2}$. Em outra ocasião, diante de compostos nos quais o mercúrio se mostrava monovalente e supondo o mercúrio diatômico, ele acomodou a valência fixa indicando que nesse caso o metal saturava uma de suas valências com outro átomo de mercúrio $\left(\mathrm{Hg}_{2} \mathrm{Cl}_{2}\right.$ e não $\left.\mathrm{HgCl}\right)$.

A primeira edição do seu Lehrbuch der Organischen Chemie apareceu em junho de 1859. Nele, Kekulé introduziu a famosa fórmula salsicha para ilustrar sua discussão verbal sobre a constituição dos compostos orgânicos. Num artigo de 1865, Sur la constitution des substances aromatiques, ${ }^{62}$ Kekulé apresentou sua fórmula salsicha para representar em 1 uma cadeia aberta, em 2 uma cadeia fechada, em 3 o benzeno, em 4 o benzeno clorado e em 5 o benzeno diclorado, como mostra a Figura 2.

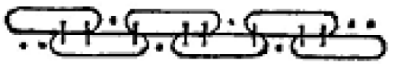

1. Chaine ouverte.

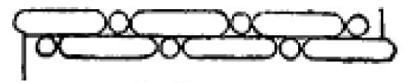

3. Benzine.
2. Chaine fermée.

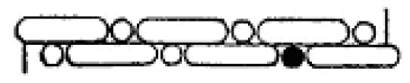

4. Benzine chlorée.
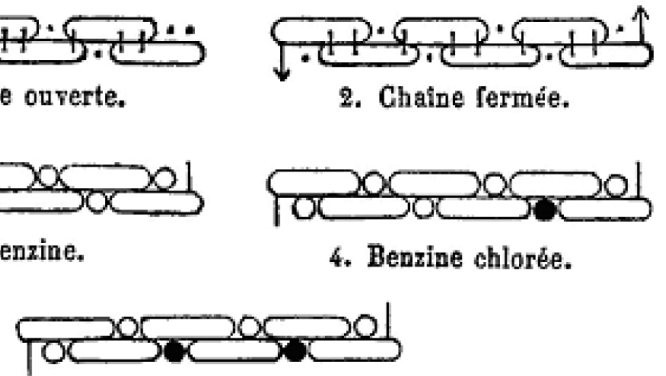

5. Benzine bi-chlorée.

Figura 2. Fórmulas salsicha de Kekulé

Sua distinção entre átomos do radical (o esqueleto de carbono em si e todos os átomos ligados direta e completamente a ele) e átomos do tipo (átomos ligados indireta ou incompletamente ao esqueleto) se tornou mais clara por meio de suas fórmulas gráficas. Kekulé reafirmou seu ponto de vista de que radicais e tipos eram conceitos meramente relativos e convencionais, mutuamente complementares. Reagentes diferentes poderiam agir sobre uma mesma molécula de modos distintos, revelando diferentes aspectos de sua constituição. Uma substância poderia ser pensada como pertencente a mais de um tipo ou como contendo diferentes radicais constituintes. Uma reação revelaria uma relação simples tipo-radical que poderia ser resumida em uma fórmula racional, isto é, uma fórmula sugerindo os grupos atômicos revelados pelas reações químicas. Várias fórmulas diferentes poderiam ser usadas para uma dada substância, dependendo da reação específica ou propriedade da substância que estivesse em discussão. Kekulé distinguia sua concepção de fórmula racional provisória, derivada das reações químicas, da crença (de Kolbe, por exemplo) que as fórmulas absolutas da constituição, expressando os grupos reais de átomos, fossem a própria meta da química teórica. Ele também distinguia átomo químico, átomo físico e arranjos ou, mais precisamente, entre os aparentes arranjos atômicos deduzidos das propriedades químicas e o verdadeiro arranjo físico (ou espacial) dos átomos na molécula. $\mathrm{O}$ primeiro estava bem dentro do território da ciência positiva e o segundo não, ou ao menos ele não era acessível por meio do estudo das reações químicas apenas. Os dois poderiam ser idênticos, porém não havia nenhum meio de verificar isso. Suas fórmulas de reação pretendiam claramente expressar ligações atômicas exatamente como elas claramente derivavam das considerações de valência.

No artigo On Some Points of Chemical Philosophy, ${ }^{63}$ de 1867,
Kekulé explicitamente rejeitou a utilidade para os químicos da hipótese de átomos físicos, "tomando a palavra no seu sentido literal de partículas indivisíveis da matéria". Ele reafirmou a distinção entre "átomo químico" e "átomo físico", identificando o primeiro com "aquelas partículas da matéria que não sofrem nenhuma divisão posterior nas metamorfoses químicas". Ele já se havia recusado a identificar a molécula química com a molécula física quando Cannizzaro, em 1860, havia proposto essa identidade. Kekulé estava entre aqueles que achavam incerto tomar a menor unidade das reações químicas - a molécula, como uma espécie que possuía uma existência autônoma na natureza.

O conceito de Gerhardt de fórmula de reação incluía uma firme negativa da possibilidade de determinar as constituições químicas. $\mathrm{O}$ uso de Kekulé do mesmo termo meramente enfatizava as bases empíricas e o status provisório de tais determinações. Outros químicos da época também faziam distinções semelhantes entre fórmula de constituição química e física. ${ }^{64}$

Alexandre Butlerov, químico russo, foi quem enfatizou o fato de que havia apenas uma fórmula absoluta para um dado composto, ao contrário das fórmulas racionais que Gerhardt e outros haviam usado, e que dependiam das várias reações dos compostos. Ele afirmou que o estudo físico das moléculas, ao invés do estudo químico de reações, era o melhor meio para conquistar um conhecimento sobre a constituição das moléculas. Butlerov foi capaz de descobrir os álcoois terciários e de explicar e prever os numerosos casos de isomeria de constituição dos esqueletos de hidrocarbonetos possuindo o mesmo número de átomos de carbono. Butlerov introduziu o termo estrutura química em 1861, em um congresso de Química em Speyer, na Alemanha, ${ }^{65}$ no qual apresentou sua famosa comunicação: Algumas reflexões considerando a estrutura química dos compostos. O ponto central desse artigo era a sua firme opinião de que o conceito de atomicidade ${ }^{66}$ podia levar a uma teoria perfeitamente geral e consistente da constituição dos compostos químicos.

\begin{abstract}
"Prosseguindo com a suposição de que existe em cada átomo químico apenas uma quantidade específica limitada de força química (afinidade), com a qual ele participa na formação dos corpos, eu designaria essa coesão química ou a maneira das ligações mútuas dos átomos em um corpo composto pelo nome de estrutura química.

A regra familiar que diz que a natureza da molécula é determinada pela natureza, quantidade e arranjo dos seus componentes elementares, poderia então temporariamente ser enunciada da seguinte forma: a natureza química de uma molécula é determinada pela natureza e quantidade de seus componentes elementares e por sua estrutura química." 67
\end{abstract}

Butlerov sugeriu que sua concepção de estrutura química levaria a fórmulas que são verdadeiramente racionais, de modo que apenas uma fórmula absoluta seria possível para uma dada substância. Definiu estrutura química como "coesão química" ou "o modo das ligações mútuas dos átomos em um composto” ou "o modo pelo qual os elementos estão quimicamente conectados" ou como "a distribuição da ação da afinidade dos átomos em uma molécula" ou ainda, em 1863, como "a maneira da (...) coesão química de átomos individuais formando um corpo complexo" e, em 1864, como "a seqüência de ação mútua - a maneira da ligação química mútua dos átomos elementares em uma molécula".

De modo moderno, Butlerov definiu estrutura química como o modo pelo qual os átomos estão quimicamente unidos para formar moléculas. Para Butlerov, "a idéia de estrutura química surge diretamente do conceito de valência." 68

A aceitação de uma valência variável para Butlerov está implícita 
a partir da idéia da utilização completa ou incompleta da afinidade do elemento. Butlerov dividia todos os elementos em dois grupos: um formado pelos elementos de valências pares e outro pelos elementos de valências ímpares. De acordo com essa divisão os elementos com valências pares poderiam existir como espécies isoladas fora de um composto. ${ }^{69}$

Num artigo de 1863, Ueber die verschiedenen Erklärungsweisen einiger Fälle von Isomerie ${ }^{70}$ (Sobre as diferentes maneiras de esclarecer alguns casos de isomeria), Butlerov introduziu o termo ligação química. Houve uma confusão inicial sobre o significado e a abrangência dos termos ligação química e valência. A valência se estabeleceu como uma característica do corpo químico e a ligação química como uma consequiência externa a ele. Para Butlerov, valência era a força contida no elemento, que poderia ser totalmente ou parcialmente convertida e se transformar na ligação química.

\section{CONCLUSÃO}

O período compreendido entre a Hipótese de Avogadro e o Congresso de Karlsruhe foi caracterizado por tensões metodológicas e epistemológicas entre os estudiosos da Química Orgânica. Com relação ao desenvolvimento do conhecimento científico, os avanços que ocorreram entre 1830 e 1860 permitiram aos químicos esclarecer fenômenos observados na primeira metade do século como, por exemplo, os casos de isomeria ${ }^{71}$ já relatados por Dalton e Faraday. Os avanços podem ser avaliados se considerarmos que a constituição das substâncias era inicialmente inferida a partir das reações químicas, isto é, o conhecimento deveria ser estabelecido sobre bases exclusivamente empíricas. Laurent e Gerhardt enfrentaram este preconceito de forma diferente, porém, apesar das diferenças, suas posições e pesquisas marcaram um momento decisivo na História da Química. Baudrimont, em 1833, também já se havia expressado contra a possibilidade de inferir a constituição a partir das reações, como se pode observar na citação abaixo:

"Uma reação química não pode ocorrer sem um movimento dos átomos. Conseqüentemente uma reação... não pode $e$ nunca será capaz de indicar o arranjo dos átomos em uma combinação (...) Uma reação, ao estabelecer um movimento molecular, destrói o arranjo precedente dos átomos. Portanto, ser capaz de obter uma substância composta de uma combinação não significa que esse composto já existisse nessa combinação."72

Laurent e Gerhardt, respectivamente, influenciaram os estudos que resultaram na teoria da estrutura e no estabelecimento dos pesos atômicos em substituição aos equivalentes. Ao mesmo tempo, também contribuíram metodologicamente ao empregarem um método de analogias para desenvolver seu trabalho. Gerhardt desenvolveu analogias formais, enquanto Laurent empregou analogias materiais, como já foi explicado. Ambos foram capazes de fazer previsões sobre compostos e produtos de reações.

Analogias já haviam sido empregadas, como por exemplo, entre a Química Inorgânica e a Química Orgânica, quando Berzelius estendeu sua teoria dualística à Química Orgânica envolvendo radicais e mecanismos de adição. "Se na Química mineral os radicais são simples, na Química orgânica eles são compostos", diziam Dumas e Liebig em 1837, ${ }^{73}$ porém com os trabalhos de Laurent e Gerhardt, a visão unitária foi substituindo a visão dualística. Essa mudança pode ser percebida pelo estudo das Teorias em Química Orgânica. Como disse Brooke, "a crise, no início dos anos 1840 foi tão grande porque o princípio de inferir a constituição a partir das reações e o princípio da analogia de Berzelius caíram em desgraça.” 74
A partir dos anos 60 o desenvolvimento da noção de estrutura baseada no conceito de valência ${ }^{75}$ permitiu explicar a natureza dos compostos aromáticos tomando como referência a estrutura do benzeno, proposta por Kekulé no artigo de 1865:

"À medida que vários átomos de carbono se combinam entre si, eles podem reunir-se de modo que uma das quatro afinidades de cada átomo se sature sempre por uma afinidade do átomo vizinho. Foi assim que expliquei as séries homólogas e em geral a constituição geral das substâncias graxas. Pode-se mesmo admitir que vários átomos de carbono se reúnem e se combinam de forma alternada por uma e por duas afinidades...

Se o primeiro modo explica a composição das substâncias graxas, o segundo explica a constituição das substâncias aromáticas, ou ao menos do núcleo que é comum a todas. Com efeito, seis átomos de carbono combinando-se segundo esta lei de simetria formarão um grupo, que considerado como uma cadeia aberta terá ainda oito afinidades não saturadas. Se, porém, admite-se que os dois átomos que terminam essa cadeia se combinam entre si, ter-se-á uma cadeia fechada possuindo ainda seis afinidades não saturadas."76

A atividade óptica deve ter sido a pedra fundamental para o átomo de carbono tetraédrico, e foi Laurent quem inspirou o respeito pelos métodos físicos, que foram tão construtivos nas mãos de Pasteur, Le Bel e van't Hoff e outros que os seguiram trabalhando numa Química em três dimensões. Entenda-se, neste período, método físico como método dedutivo, e método químico como método indutivo ou empírico. Diferentemente, Gerhardt defendia que espécies químicas deviam ser distinguidas apenas por métodos químicos. Trabalhar em três dimensões permitiu explicar a propriedade de certos isômeros de desviar o plano da luz polarizada para a esquerda ou para a direita. Tratava-se de traduzir em termos de estrutura, isto é, na escala atômica, as observações de Pasteur sobre a assimetria cristalina dos ácidos tartáricos. Esse novo argumento foi fornecido por Joseph A. Le Bel e Jacobus van't Hoff que simultaneamente, em 1874, formularam a noção de carbono tetraédrico, que permitia explicar a assimetria molecular.

A partir de 1870 o conceito de valência associou-se ao de periodicidade e passou a ser empregado nos campos acadêmico e didático. Um dos primeiros livros didáticos britânicos a usar o sistema periódico foi Principles of Chemistry de Pattison Muir, publicado em 1884. ${ }^{77}$ Sua concepção de átomo e molécula estava ajustada a uma nova Química, mostrando como Cannizzaro havia sido completamente adotado.

Mendeleev trabalhou na obtenção de uma regularidade na periodicidade química dos elementos aproximadamente por quinze anos. Ele verificou sistematicamente todas as propriedades químicas mensuráveis disponíveis na época: volume atômico, isomorfismo, composição dos compostos e massa atômica. Meyer em 1864 havia apresentado uma tabela, na qual os elementos eram arranjados em seis colunas de acordo com suas valências. Mendeleev também elaborou tabelas, nas quais os elementos eram organizados em relação a sua valência em óxidos e haletos. Inicialmente, ele comparou a variação da massa atômica e do volume atômico com a valência. Em seguida considerou o isomorfismo em função da valência e formulou três regras, sendo que as duas primeiras correlacionavam as diferentes formas dos compostos com as suas valências.

Foi somente em 1870 que Mendeleev finalmente resolveu o problema da unificação e formulou o princípio básico de seu sistema: " $a$ distribuição natural dos elementos em grupos, de acordo com seus pesos atômicos, corresponde à quantidade máxima de oxigênio que 
o elemento pode incorporar na forma de um óxido salino." 78

Durante esse período em que os conceitos fundamentais e as questões relacionadas com a estrutura atômica das substâncias estavam sendo gerados, pode-se destacar ainda a inversão que ocorreu entre os conceitos de átomo e molécula: átomos tornaram-se subordinados a moléculas e equivalentes subordinados a átomos. A partir de 1860 , isto é, a partir do Congresso de Karlsruhe, os pesos atômicos passaram a ocupar o interesse central dos químicos. No ensino, o precavido indutivismo foi cedendo espaço para também incorporar uma Química organizada de modo dedutivo com a inclusão da Hipótese de Avogadro e do Sistema Periódico nos livros de Química.

Os conceitos fundamentais para o desenvolvimento da nova Química foram abordados, neste trabalho, de acordo com a história do seu surgimento e juntamente com as possíveis indagações metodológicas e epistemológicas que acompanharam o seu desenvolvimento. Os desdobramentos mais imediatos e importantes desses conceitos foram apontados, para que possamos perceber a linha conceitual na qual estão inseridos. Seguindo a diferenciação entre átomo e molécula, o processo lento de substituição dos pesos equivalentes pelos pesos atômicos, e a contribuição da Teoria dos Tipos para o conceito de valência e de estrutura, é possível perceber como esses conceitos se articularam no passado e como o atomismo se foi estabelecendo na Química.

Como Kekulé escrevera em 1867: "o programa do atomismo químico não foi baseado na suposição da real existência dos átomos considerados como partículas indivisíveis, porém na aplicação do atomismo para a explicação das reações químicas e da estrutura dos compostos químicos." ${ }^{\text {79 }}$ Desta maneira, o atomismo inicialmente heurístico se foi tornando gradualmente ontológico. O cuidado observado por cientistas como Kekulé, em distinguir os aparentes arranjos atômicos deduzidos das propriedades químicas do verdadeiro arranjo físico (ou espacial) dos átomos na molécula, já demonstra que a realidade atômica havia sido admitida.

\section{REFERÊNCIAS E NOTAS}

1. A distinção entre Química Orgânica e Inorgânica foi expressa pela primeira vez por Bergman em 1780. Nos séculos XVI e XVII, as substâncias eram identificadas de acordo com as suas origens. Essas fontes eram os reinos animal, vegetal e mineral; Leicester, H. M.; The Historical Background of Chemistry, Dover: New York, 1971, p.172.

2. Frické, M. Em Method and Appraisal in the Physical Sciences; Howson, C., ed.; Cambridge University Press, 1976, p. 277-307.

3. Dalton, J., A New System of Chemical Philosophy, Part I, Manchester, 1808; Part II, Manchester, 1810; Part First of Vol. II, Manchester, 1827.

4. Crosland, M. P. Em Dictionary of Scientific Biography; Gillispie, C., ed.; Scribner: New York, 1970-1980, vol. 1, p. 343-350. Os termos parte integrante, molécula primitiva integrante, e parte constituinte não são originais de Avogadro e já constavam do Dicionário de Química de Macquer de 1766. Os termos molécula integrante, molécula constituinte e molécula elementar são citados no livro Systèmes de Connaissances Chimiques, de Fourcroy, de 1800. No verbete "Agregação", Macquer define partes constituintes como os princípios que formam os corpos. "Por exemplo, as partes constituintes do sal comum são um ácido e um álcali, que devem ser considerados como os princípios desse sal... é evidente que as partes constituintes não podem ser desunidas sem destruir e decompor o sal: de modo que após a desunião, o sal não mais existirá...”. Ele define também partes integrantes de um corpo como as menores moléculas ou partículas nas quais este corpo pode ser reduzido sem decomposição. Essas menores moléculas que no exemplo dado ainda seriam de sal são aquelas que Macquer denominou molécula integrante primitiva. A união de partes integrantes resultaria em agregados, que são a reunião de um certo número de partes do mesmo tipo formando um todo, e que se opõem ao que denominamos misto ou compostos (Macquer, 1777, apud Crosland, M. P., ed.; The Science of Matter: Selected Readings, Penguin: Londres, 1971, p. 156).

Fourcroy indicava que os corpos eram formados pela reunião de um grande número de moléculas integrantes através da força de agregação. Cada uma dessas moléculas podia por sua vez ser formada pela reunião de várias moléculas constituintes que correspondiam aos "princípios", ou elementos que formam os compostos.

5. Pesos equivalentes correspondem às quantidades em massa que expressam a menor proporção em massa entre substâncias que reagem.

6. Bensaude-Vincent, B., Les Atomes: Une Anthologie hHistorique, Agora : Paris, 1991, p. 13.

7. Segundo Lavoisier, os ácidos eram compostos binários de um radical com o oxigênio; Ihde, A.; The development of modern chemistry, Harper \& Row: New York, 1970, p. 184.

8. Kapoor, S. C. Em Dictionary of Scientific Biography; Gillispie, C., ed.; Scribner: New York, 1970-1980, vol. 1, p. 242-248.

9. Dumas, J. B. ; Traité de Chimie Appliquée aux Arts, Bechel: Paris, 1828, vol. 1, p. xxxiv.

10. Frické, M.; op. cit., p. 277-307.

11. Ihde, A.; The Development of Modern Chemistry, Harper \& Row: New York, 1970, p. 186-187.

12. Nye, M. J.; Before Big Science: the Pursuit of Modern Chemistry and Physics, 1800-1940, Harvard University Press: Cambridge, 1996, p. 42.

13. Brooke, J. H.; Laurent, Gerhardt, and the Philosophy of Chemistry. Historical Studies in the Physical Sciences, 1975, 6, 405-429.

14. Brooke, J. H.; op. cit., p. 405-429.

15. Modernamente o radical acetil corresponde a $\mathrm{C}_{2} \mathrm{H}_{3} \mathrm{O}$ e não $\mathrm{C}_{2} \mathrm{H}_{3}$, conforme Liebig considerava.

16. Dumas, J. B.; 1834, apud Ihde, A. J., op. cit.

17. Seu conhecimento de cristalografia mineral e isomorfismo químico seguiam a tradição de René-Just Haüy e Eilhardt Mitscherlich, respectivamente. Em torno de 1820, Mitscherlich havia observado que os fosfatos e arseniatos de um mesmo metal possuíam a mesma forma cristalina. Ele estendeu suas observações a outros sais minerais e chegou finalmente à seguinte conclusão: o mesmo número de átomos elementares combinados do mesmo modo produz a mesma forma cristalina e essa forma é independente da natureza química dos átomos. Ela é determinada apenas pelo número de átomos e pelo seu arranjo. De acordo com a lei do isomorfismo é possível substituir, em pensamento, um fósforo pelo arsênio no fosfato sem que o edifício molecular seja modificado. Laurent aplicou este princípio às reações de substituição na sua Teoria do Núcleo.

18. Laurent, M. A.; Recherches sur les combinaisons azotées. Ann.Chim et Phys., Paris, 1846, 18, p. 295-296.

19. Laurent, A.; 1855 apud Brooke, J. H.; op. cit., p. 405-429.

20. Brooke, J. H.; op. cit., p. 405-429.

21. Leicester, H. M.; op. cit., p.178.

22. Ihde, A. J.; op. cit., p.196.

23. Nye, M. J.; op. cit., p.124.

24. Dumas, J. B.; Comptes Rendus 1840, 10, 149-178.

25. Ihde, A. J.; op. cit., p. 205.

26. Sua oposição a Dumas custou-lhe uma sobrevivência difícil, com tutorias de alunos particulares e sem ser aceito nos principais centros de pesquisa da França. Só conseguiu ser aceito pela Universidade de Estrasburgo, um ano antes da sua morte, com quarenta anos.

27. Ihde, A. J.; op. cit., p. 206. Em termos modernos a equação de Gerhardt é escrita da seguinte forma: $\mathrm{C}_{2} \mathrm{H}_{6} \mathrm{O}+\mathrm{HNO}_{3} \rightarrow \mathrm{C}_{2} \mathrm{H}_{5} \mathrm{NO}_{3}+\mathrm{H}_{2} \mathrm{O}$.

28. Brooke, J. H.; op. cit., p. 405-429.

29. Taton, R., org. ; La Science Contemporaine, em Histoire Générale des 
Sciences, Quadrige: Paris, 1961, Tomo III, vol.1, p. 325.

30. Leicester, H. M.; op. cit., p.183.

31 e 32. Meyer, L.,1891, apud Fisher N. W.; History of Science 1982, 20, p. 212-231.

33. Entenda-se por meias moléculas de hidrogênio $\left(\mathrm{H}_{2}\right)$ o que modernamente corresponde ao átomo de hidrogênio $(\mathrm{H})$, de acordo com as citações de 1833 e de 1873 do próprio Gaudin.

34. Gaudin, M. A.; Recherche sur la structure intime des corps inorganiques defines. Ann. Chim. Phys. 1833, 52, 113-133.

35. Cole, T. M., 1975, apud Brooke, J. H.; Avogadro's Hypothesis and its Fate: a Case-Study in the Failure of Case-Studies. His. Sci, 1981, 19 , 235-273.

36. Frické, M. ; op. cit., p. 277-307.

37. Gaudin, M. A. ; L'Architecture du Monde des Atomes Dévoilant la Structure des Composés Chimiques et leur Cristallogénie, GauthierVillars: Paris, 1873, p. 24-25.

38. Nye, M. J.; op. cit., p.126.

39. Ihde, A. J.; op. cit., p. 212.

40. Williamson W., apud Benfey O. T., apud Nye, M. J., op. cit., p.127.

41. Cannizzaro, S., 1858, apud Brooke J. H.; His. Sci. 1981, 19, 235-273.

42. Palmer, W. G.; Valency: Classical and Modern, Cambridge University Press, 1959, p. 14

43. Palmer, W. G.; ref. cit., p. 14.

44. Maxwell, J. C.; Atom, em The Scientific Papers of James Clerk Maxwell, Cambridge University Press, 1890, Dover Publications, 1965, p. 445484 .

45. Fisher N. W.; His. Sci. 1982, 20, 212-231.

46. Partington nasceu em 1886 e foi educado enquanto Meyer ainda exercia grande influência. Partington, 1964, apud Fisher N. W.; His. Sci. 1982, 20, 212-231

47. Fisher N. W.; His. Sci. 1982, 20, 212-231.

48. Frankland, 1852, apud Palmer, W. G.; op. cit., p. 9.

49. Os termos monoatômico, diatômico... etc, já eram conhecidos, como Marc-Antoine Gaudin propõe em Recherche sur la Structure Intime des Corps Inorganiques Définis, Annales de Chimie et Physique, 1833, 52, 113-133: "Estabeleceremos, portanto uma distinção bem marcada entre os termos átomo e molécula, e isto com muito mais certeza, pois se até hoje não se chegou às mesmas conclusões que eu, foi unicamente por não se ter estabelecido essa distinção. Um átomo será para nós um pequeno corpo esferóide homogêneo, ou ponto material essencialmente indivisível, enquanto uma molécula será um grupo isolado de átomos, em qualquer número e de qualquer natureza. A fim de evitar as repetições e em vez de dizer: uma molécula composta de 1, de 2, de 3, de 4, de 5, de muitos átomos, etc, faremos o adjetivo monoatômico, diatômico, triatômico, tetratômico, pentatômico, poliatômico, etc. acompanhar o substantivo molécula". Ainda em outra passagem do mesmo artigo: "Consideremos as combinações de gases. Desde que as partículas estejam mantidas a uma mesma distância, por uma mesma pressão e temperatura, diremos 1, 2, 3 partículas, em vez de 1, 2, 3 volumes e substituiremos mesmo o termo partícula pelo termo molécula, uma vez que agora, o termo partícula é considerado como contendo vários átomos".

50. Segundo Leicester, H.; op. cit., p.184, o nome valência foi introduzido por C. W. Wichelhaus em 1868

51. Palmer, W.G.; op. cit., p.15.

52. Kekulé, 1858, apud Rocke, A. J.; Brit. J. Hist. Sci. 1981, 14, $27-57$.
53. Brush, S.; The Kind of Motion We Call Heat, North-Holland, 1976, New York, vol. 1, p. 172

54. Kekulé, A.; Ueber die s. g. gepaarten Verbindungen und die Theorie der mehratomigen Radicale, Annalen der Chemie und Pharmacie 1858, 104 (2), 129-150.

55. Rocke, A. J.; op. cit., p. 31.

56. Ihde, A. J.; op. cit., p. 222.

57. Kekulé, A. ; Ueber die Constitution und die Metamorphosen der chemischen Verbindungen und über die chemische Natur des Kohlenstoffs, Annalen der Chemie und Pharmacie 1858, 106, 129-159.

58. Kekulé, A. ; 1858, apud Nye, M. J. ; op. cit., p. 130.

59. Couper, que trabalhava com Wurtz no laboratório de Paris, havia desenvolvido essencialmente a mesma teoria que Kekulé, porém seu trabalho foi publicado poucas semanas após o deste último. Couper expressou as ligações de afinidade por linhas retas como são representadas atualmente as ligações químicas. Diferentemente, Kekulé usou diagramas que não se mostraram convenientes para uma visualização da estrutura real (Leicester, H. M.; op. cit., p. 185). Os dois artigos pretendiam mostrar que um conhecimento maior sobre as fórmulas dos compostos orgânicos poderia ser obtido de modo melhor a partir de um estudo dos elementos constituintes e seu modo de combinação que do estudo dos radicais.

60. Nye, M. J.; op. cit., p.130.

61. Palmer, W. G.; op. cit., p. 11.

62. Kekulé, F. A.; Sur la constitution des substances aromatiques, Bulletin de la Societé Chimique de Paris 1865, 3, 98-110; logo em seguida, ele publicou na Alemanha o artigo Untersuchungen über aromatische Verbindungen, em Liebigs Annalen der Chemie 1866, 137, 129-136.

63. Kekulé, 1867, apud Freund, I.; The Study of Chemical Composition, Dover: New York, 1968, p. 624.

64. Rocke, A. J.; op. cit., p. 34.

65. Leicester, H. M.; op. cit., p. 185.

66. O termo atomicidade era usado no lugar do termo valência.

67. Butlerov, A. M.; 1861, apud Rocke, A. J.; op. cit., p. 35.

68. Butlerov, A. M.; 1864-6, apud Rocke, A. J.; op. cit., p. 37.

69. Kuztznetov, V. I., org.; Theory of Valency in Progress, Mir Publishers: Moscou, 1980, p. 53.

70. Butlerov, A. M.; 1953, apud Kuztznetov, V. I.; op. cit., p. 48.

71. Chevreul, em 1823, havia sugerido que uma explicação para o problema dos isômeros só seria possível recorrendo a arranjos diferentes dos átomos ou partículas.

72. Baudrimont, A. E.;1833, apud Brooke, J. H.; op. cit., 405-429.

73. Taton, R.; op. cit., p. 321.

74. Brooke, J. H.; op. cit., 405-429.

75. Valência neste parágrafo corresponde ao termo atomicidade, empregado na época, e que significava poder de combinação.

76. Kekulé, F. A.; Bull. Soc. Chim. France. Paris 1865, 3, 98-110.

77. Muir, M. M. P.; A Treatise on the Principles of Chemistry, Cambridge, 1884, apud Fisher N. W.; His. Sci. 1982, 20, 212-231.

78. Dmitriev, I. S.; Scientific Discovery in Statu Nascendi: the Case of Mendellev's Periodic Law. Issues His. Sci. Thecnol 2001, n.1, 31-82.

79. Harman, P. M.; Energy, Force and Matter, the Conceptual Development of Nineteenth-Century Physics, Cambridge University Press, 1995, p.126. 